\title{
Game Analysis on Benefits Relationship in the Strategic Innovation Process of Rural Credit Cooperatives
}

\author{
Y.P. Liu \\ School of Software Engineering, Beijing University of \\ Technology \\ Beijing, China
}

\author{
P.N. Ruan \\ School of Economics and Management, Beijing \\ University of Technology \\ Beijing, China
}

\begin{abstract}
The strategic cooperation of rural credit cooperatives (RCCs) involves different stakeholders, including government, RCC and various strategic partners. In this paper, a framework of game analysis for them was constructed and conclusions were as follows. If option mastery was under control of government, the result of strategic cooperation would be that governor was likely to reduce the supporting subsidies to $\mathrm{RCC}$, in the meanwhile, profit levels increased. Otherwise, if under control of RCC and managers had more
\end{abstract}

Keywords-Rual Credit Cooperatives; starategic cooperation;partner;benefits relationship; game analysis;

\section{INTRODUCTION}

Chinese central government has issued its first policy document for 2015, which advocate to adopt a proactive approach in satisfying actualities of rural areas, characteristics of agriculture and needs of farmers. It also advocates to continuously deepen financial reform and innovation in rural areas, promote capital strength and governance level of rural credit cooperatives (RCCs), solve three rural issues based on country area, as well as enhance inclusive finance in rural areas. Due to the imbalance of economic development in different rural areas, rural finance features the diversification and personalization of needs. Under this circumstance, currently RCCs face both opportunities and challenges, including changes in basis and conditions, service objects as well as needs for the development of rural finance under new normal economy, changes in policies involving reform of mixed ownership, interest rate liberalization and deposit insurance system, changes in demands of the whole-industrial-chain financial services and comprehensive financial business innovation, as well as changes in market competition from Internet finance and private banks, all of which push changes in the needs of rural finance. Up to now, qualification share of RCCs nationwide has decreased to $1 \%$, achieving the aim of RCC reform put forward by China Banking Regulatory Commission (CBRC), which strives to cancel qualification share of RCCs before 2015 and encourage qualified RCCs to reorganize into rural commercial banks.

RCCs must meet the objective requirements of economic development concerning three rural issues and keep improving qualities of financial services so as to achieve long-term development. However, problems exist in the reform process of RCCs. Firstly, due to the unclear property right structure and absence of owner-subject caused by passive participation, administrative intervention of local government and province cooperative union is pronouncing[1]. Secondly, the unsound management system and imperfect contract of principalagent lead to internal control and information asymmetry, thus providing condition for dissimilation of managers. High rate of non-performing loan and problems left over by history cause management crisis. Thirdly, financial services lack innovation with single financial products. Due to outdated innovation philosophy, weak innovation basis and insufficient innovation impetus, financial innovation led by RCCs cannot satisfy demands of market[2].

Introduction of strategic cooperative partners is the inevitable choice of RCCs. In fact, rural financial service agencies have made progress in the practice of introducing strategic cooperative partners. For instance, Shanghai Rural Commercial Bank Co. Ltd. has signed strategic cooperation agreement with Australia and New Zealand Banking Group; Rabobank and International Finance Corporation have $10 \%$ and $5 \%$ of shares of Hangzhou United Rural Cooperation Bank respectively; Binhai Rural Commercial Bank of Tianjin has introduced International Finance Corporation as its strategic investor. There are also rural cooperative financial agencies who introduce domestic strategic investors. Nevertheless, problems exist in the introduction process, which affecting the stable development of rural financial agencies. For example, the reasonablity of cooperation model and profit distribution model have a direct influence on the sustainability and stability of the cooperation between RCCs and their strategic partners, and can even affect the performance and function of cooperative agencies.

\section{DEFINITION OF STRATEGIC COOPERATIVE RELATION} OF RCCS

RCC's selection of strategic cooperative partners involves not only its own operation reform but also other stakeholders in the rural economic environment, the major one of which is local governments assuming macro-control function, including governments and administration authorities that can invest and supervise RCCs such as provincial government, province cooperative union, country government and country cooperative union. 


\section{A. Research on Strategic Cooperative Relation}

Selection of strategic partners and management of strategic cooperative relation are one important aspect of modern business management, in which high failure rate of strategic alliance attracts the great attention of scholars worldwide. According to the research of Duysters, causes of alliance failure include strategic mismatch of partners, incompatibility of alliance culture, lack of trust and efficient performance evaluation approach among the alliance, inability to fulfill promises, as well as unsound management structure[3].

Strategic cooperative relation arises under complex economic and social background. Lambe and Spekman points out that the uncertain industrial structure and market environment promotes the establishment of strategic cooperative relation[4]. According to Vokurka, strategic cooperative relation is promise and agreement with effect in a relative long time made by two parties from upstream and downstream of one industry chain, featuring information sharing and risk pooling, which indicates the concept of partner is rooted in cooperation and trust[5].

A number of scholars have given definition to strategic cooperative relation. Bleeke and Emst hold that strategic partners formed in independent enterprises enables them to have common goals and value their relationship based on mutual trust, thus achieving goals that cannot be fulfilled by each independent enterprise alone through concerted efforts[6]. In other words, the original intention of establishing such cooperative relation is to gain competitive advantages. Maloni and Breton define strategic cooperative relation as the coordination relationship of two or more independent parties to ensure the achievement of a certain goal and benefit[7].

\section{B. Research on Chinese RCC Reform}

According to institutional economists, selection of partners is an issue concerning benefit distribution, in which the participators include local government, RCC and partner while the way to solve the issue is to find the suitable institutional evolution path. Nevertheless, mainstream economists are more likely to apply game theory to analyze how to maximize benefits of RCC and what attitude and strategies RCC should take in the process of strategic cooperation. The difference from two perspectives lies in the difference in analysis paradigm. In other words, the pointcut of institutional economics is how to save transaction costs[8], on which basis boundary problems of local government, RCC and partner are analyzed. Game analysis is the tool of mainstream economics to analyze such issues, which is based on benefit maximization of all parties in the strategic cooperation, ensuring the possible strategic decisions in rational situation[9]. In recent years, concerning the development of RCCs under the socialist system with Chinese characteristics, Chinese scholars begin to use game theory as tool to analyze the complex relationship among stakeholders of RCCS.

$\mathrm{Li}$ Qi holds that the evolution process of Chinese RCC system is the game and balance process of four stakeholders including central government, local government, staff of RCC and insiders[10].

Based on game analysis of local government and RCC, Wei Jinming concludes that under current management system local government is still possible to intervene RCC, and that incentive and restricting measures actively taken by provincial government such as regulatory tax rate can prevent improper intervention of local government to RCC[11].

Through game analysis between RCC and financing of disadvantageous farmers, Kong Rong finds that under the condition of incomplete information, RCC's fear for decrease of its benefits due to farmer's breach of contract result in failure of petty loans while under the condition of trust, both disadvantageous farmers and RCC know each other will take the strategy of cooperation so that trust will ensure the success of debiting and crediting[12].

Zhang Lezhu assumes local government and RCC as game players and analyzes from the perspective of cooperation game, holding that for RCC construction, local government's advantage in administrative power and government authority, combined with RCC's advantage in capital and human resources can efficiently promote the development of RCC and display RCC's role in solving problems concerning farmers' difficulties in obtaining loans[13].

Base on the analysis of current supply and demand conditions of rural credit market under asymmetric information, Zhang Yaofeng sets up evolutionary game model of RCC-farmer relationship, applying replicated dynamic equation and stability theory to analyze the evolutionary rules[14].

To sum up, research above covers analysis paradigm of non-cooperative game, cooperative game and dynamic game, the object of which centers on such stakeholders as local government, RCC and farmer. However, another important aspect of RCC reform, i.e., the introduction of strategic cooperative partners is rarely included in such game analysis.

\section{Stakeholders in RCC's Strategic Cooperation}

According to basic assumptions of economics, three stakeholders including RCC can be regarded as "economic man", whose aim of all strategies and actions in strategic cooperation is benefit maximization. In reality, they are not entirely rational but relatively rational. It is without doubt that local government is the dominant of strategic cooperation. Thus, under the economic policy system of local government, RCC has to bargain with local government in the selection of strategic partners based on its own benefits. Although how to utilize economic strength of partners is one factor of game, the essence of game is between local government and RCC, which embodies the inter-substitution of local government, RCC and strategic partner.

As "economic man", local government is responsible for not only guidance of local economic development but also supervision and coordination of RCC reform. Decisions made by RCC are key to the success of strategic cooperation. The strategic goal of RCC is not only maximization of its own benefits but also to organize rural funds in the true sense and provide financial services for the development of agriculture, farmers and rural economy. Taking the two aspects into consideration is the essential condition of RCC to display its fundamental role. Since interests of local government and RCC can be consistent or not, condition and potential possibility of game analysis 
exist. From the perspective of information economics, local government can be viewed as principal and RCC as agent. In a sense, game between local government and $\mathrm{RCC}$ is asymmetric information game.

Thereby, this thesis bases itself on triangular analytical framework of institutional economics and combines thoughts of game analysis to establish trilateral game model of RCC strategic cooperation reform with the am of making a better and deeper analysis of interrelation of local government, RCC and strategic cooperative partner, thus making sense the dominant mechanism of intersubstitution of the three stakeholders and then predicting their possible strategies and actions for benefit maximization.

III. TRILATERAL GAME MODEL OF STRATEGIC COOPERATION PROCESS

\section{Fundamental Assumptions of Trilateral Game Model}

In the process of strategic cooperation reform, RCC has two contradictory needs. On the one hand, as an important financial agency, RCC is committed to the maximization of its benefits and therefore reluctant to provide loans considering high risk and low profit of agriculture, thus failing to promote rural economy. On the other hand, once economy of one rural area encounters bottleneck, the development of RCC at the rural area will be affected, thus further enlarging the gap among different regions and departments and even strengthening dual economic structure.

Local government plays dual role in RCC's strategic cooperation. Local government is a self-interest organization responsible for the development of local economy, as well as a neutral supervisor in law that maintains the stability and order of financial system. However, in some cases, in order to direct the development of RCC, local government has to make rules to restrict the autonomy of RCC. It is worth noting that the internal interests within local government are not entirely consistent and that administrative departments at different level have contradicting interests. Nevertheless, the primary task and goal of local government is to maintain the stable development of economy, relief predicaments faced by rural finance agencies, and strengthen RCC's competence in the promotion of rural economy. Assumptions of local government are as follows.

Assume that local government possesses properties of a rational economic man who has no prejudice in administration and supervision. However, in practical management process, considering that local government is composed of relevant directors, group decision making depends that the economic polices of local government cannot be entirely neutral. Therefore, one subject that should be included in trilateral game are the directors of local government, whose maximizing behavior represents the maximizing behavior of local government. In the performance of local government's social administration and service function, their strategic decisions are of high autonomy due to different understanding of policies concerning three rural issues as well as needs of RCC.

\section{E. Utility Function of Local Government}

Decisions of local government are of multiply goals. The primary goal of local government is to promote three rural economic development. The secondary is to intensify administrative mechanism reform of local government.
Another is to push benefit maximization of RCC and its strategic partner. Therefore, assume that the utility function of local government is:

$$
\begin{aligned}
& U_{g}=U_{g}(p, M, T x, T, A)= \\
& g(T x)-g(p) c(T)+h(p) I(A)+M
\end{aligned}
$$

Where, $A$ refers to monetary profits obtained from local government's supervision in RCC's strategic cooperation reform out of needs for three rural development. Obviously, enhancement of supervision can promote regulation and control ability of local government as well as maintain the sustainable development of three rural economy. It is worth making clear that local government's supervision function must be independent of RCC's operation function, which is quasi concave function of profit level of local government or its directors, namely, $I^{\prime}(A)>0, \quad I^{\prime \prime}(A)<0$

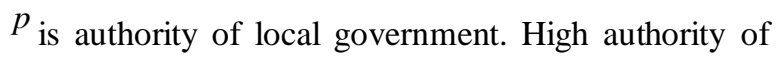
local government means greater influence on RCC's strategic cooperation reform as well as more benefits such as great decrease of management costs. Economic policy authority is one utility of local government. If director of local government possesses higher authority $p$, he is likely to provide more guarantee policies for some RCCs and gain more profits from quick development of RCCs; and vice versa. Thereby, $h^{\prime}(p)>0$.

$M$ refers to benefits of RCC gained from strategic cooperation reform, which is proportional to profits of monetization gained by local government.

$T x$ refers to benefits of three rural economy gained from RCC's strategic cooperation reform, which means rural area benefits from RCC's strategic cooperation reform, thus promoting development of three rural economy. Since benefits of three rural economy may be contradicted to RCCs' strategic plans, local government has to regard standardization of cooperation mechanism and financial risk aversion as primary purpose of its supervision in strategic cooperation process. $T x$ can be also noted as elevation of three rural economy level.

$T$ refers to transfer payment of local government for RCC's strategic cooperation reform, namely, relevant subsidies. Here the concept of subsidies can be understood from two aspects. They can be direct subsidies with form of money, mandatory low interests, interest-free loans, as well as tax cuts and returns. For example, in order to motivate RCC to join strategic cooperation, local government may offer certain subsidies or tax exemptions. Besides, subsidies can also mean local government's invention to $\mathrm{RCC}$, referring to all resources controlled by local government but beneficial to RCC's reform.

$g(T x)$ C's strategic cooperation reform. If RCC's strategic cooperation reform lays positive impact on the improvement of rural economy, local government can achieve better performance and upgrading of three rural industry structure can bring more profits of monetization. However, while emphasizing sustainable development of economy, local government cannot neglect problems 
brought by institutional reform. Therefore, the highest level of strategic cooperation is not the aim local government pursues, and benefits that local government gains from RCC's strategic cooperation reform are of upper limit to some extend. Besides, too strict supervision is not advantageous to the development of RCCs. Thus, $g^{\prime}(T x)>0, g^{\prime \prime}(T x)<0$

$c(T)$ refers to costs generated by local government's transfer payment for RCC's strategic cooperation reform, equivalent to negative tax, in which $c^{\prime \prime}(T)>0$.

\section{F. Utility Function of RCC's Strategic Cooperation}

As an important part of three rural economy, RCC possesses dual identities, which is not only the basic unit to promote sustainable development of three rural economy but also pursues maximization of its own benefits. Therefore, one purpose of RCC to launch strategic cooperation is to reduce depletion of local government financial funds at a given size and take this as condition to ask for local government's approval for further development of RCC.

Assume that the highest profit level of RCC after strategic cooperation is $\pi$, and that decision power of strategic cooperation owned by local government is $1-\alpha, \alpha \in[0,1]$. As for existing RCC strategic cooperation relation, $\alpha=0$ while for cooperation relation that is not established, $\alpha=1$. Local government is sensitive to and cautious about RCC's introduction of strategic cooperative partner. If local government doubts the cooperative partner selected by RCC but cannot impose too much pressure, $0<\alpha<1$. In this case, managers of RCC have same level of decision power for strategic cooperation, which represents local government's delegating power to RCC, allowing RCC to establish strategic cooperative relation in accordance with three rural policies with organizations of different background at its own will.

$$
\begin{aligned}
& U_{e}=U_{e}(T x, T, M)=e(T x)+ \\
& b(a p+T-T x-k A)+h(A)-M
\end{aligned}
$$

$e(T x)$ refers to monetary benefits gained by managers of RCC after strategic cooperation reform. The more economic and cooperative profit is, the higher utility of monetization is $e^{\prime}(T x)>0, e^{\prime \prime}(T x)<0$. Besides, it is important for managers of RCC to strengthen sustainable development and control ability. Therefore, $h^{\prime}(A)>0$. Economic policies of local government can directly cause RCC to lose certain cooperation opportunity and result in profit loss to some extent. Assume that the profit loss is equivalent to certain proportion of benefits of local government. Therefore, $e(T x)=0, h(A)=0$. Then, Equation (2) can be written into:

$$
U_{e}=U_{e}(T x, T, M)=b(a p+T-T x-k A)-M
$$

For analysis, here assumes that divergence exists in $\mathrm{RCC}$ and local government interest relation, which means they cannot gain more monetary benefits from benefits of strategic cooperation. In fact, whether taking this into consideration will not affect the basic conclusion on that condition that operation performance of RCC and benefits gained from the improvement of three rural economy are separable.

Subsidies provided by local government for RCC's strategic cooperation reform are decided by directors of local government, the amount of which can be also depended by the consultation between managers of RCC and directors of local government. In the process, to what extent RCC can decide cooperative benefits is measured by $T x$. On the condition that the optimal size of RCC is set, managers of RCC make sure the maximization of benefits by negotiating the size of $T x, T$ and $M$ with directors of local government.

THREAT POINT OF LOCAL GOVERNMENT AND RCC

Threat point of game subject means the minimum gains. The follow will solve the threat point of local governmental directors and RCC managers respectively.

\section{G. Local Government's Control over Cooperative Profit Level}

If director of local government possesses enough decision power, the maximization issue he faces is how to balance financial subsidies provided for RCC and three rural economic benefits brought by strategic cooperation for the maximization of local government's comprehensive utility on the condition that the participation and control of RCC managers is fulfilled.

$$
\begin{aligned}
& \max _{T, T x}[g(T x)-g(p) c(T)+h(p) I(A)] \\
& \text { s.t.b }(p+T-a T x-k A)>\bar{u}
\end{aligned}
$$

$\bar{u}$ in Equation (4) is the reservation utility of RCC managers. Lagrange equation is applied to solve the maximization issue of directors.

$$
\begin{aligned}
& L=g(T x)-g(p) c(T)+h(p) I(A)+ \\
& l[b(p+T-a T x-k A)-\bar{u}]
\end{aligned}
$$

Here lies first order condition:

$$
\begin{gathered}
g^{\prime}(T x)-\lambda \beta=0 \\
g(p) c^{\prime}(T)-l b=0 \\
h(p) I^{\prime}(A)-l b k=0
\end{gathered}
$$
(8).

The follow is obtained by solving Equation (6), (7) and

$$
g^{\prime}(T x)=g(p) c^{\prime}(T)
$$




$$
\begin{aligned}
& T=\frac{\bar{u}}{\beta}+T x-\alpha \pi \\
& h(p) I^{\prime}(A)=l b k
\end{aligned}
$$

Therefore, threat point is jointly decided by (9), (10) and (11).

\section{H. RCC's Control over Cooperative Profit Level}

If it is RCC manager who decides profit level of strategic cooperation, equilibrium solution can be defined as:

$$
\begin{gathered}
T=\max [\mathrm{g}(T x)-g(p)+h(p) I(A)] \\
T x=b(a p+T-T x-k A)-\bar{u}
\end{gathered}
$$

Obviously, equilibrium solution must be $T^{*}=T x^{*}=0$, which means there is no cooperative benefit. This is the typical "prisoner's dilemma"; and game result is not Pareto optimal solution.

\section{Joint Optimal Solution}

Considering that $M=0$, game of local government director and RCC manager reaching Nash equilibrium means maximized benefits of both parties. In this case,

$$
\max _{T, T x}\left[\begin{array}{l}
g(T x)-g(p) c(T)+h(p) I(A) \\
+b(a p+T-T x-k A)
\end{array}\right]
$$

By solving simultaneous equation of first order condition, there is

For $T x$.

$$
g^{\prime}(T x)=\beta
$$

For $T$ :

$$
\begin{aligned}
& \beta=g(p) c^{\prime}(T) \\
& h(p) I^{\prime}(A)=b k
\end{aligned}
$$

By combining Equation (15) and (16), there is

$$
g^{\prime}(T x)=g(p) c^{\prime}(T)=\beta
$$

From the results, it can be seen that local government demands the marginal increase of three rural economic benefits and profit level of RCC's strategic cooperation, which is consistent to marginal subsidies provided for RCC. Both are constants.

By solving total differential of $T x$ and $\beta$ respectively in two sides of Equation (15), the follow is obtained:

$$
\frac{\partial T x}{\partial \beta}=\frac{1}{g^{\prime \prime}(T x)}<0
$$

By solving total differential $T$ of $\beta$ and respectively in two sides of Equation (16), the follow is obtained:

$$
\frac{\partial T x}{\partial \beta}=\frac{1}{g(p) c^{\prime \prime}(T)}>0
$$

By solving total differential of $A$ and $\beta$ respectively in two sides of Equation (17), the follow is obtained:

$$
\frac{d A}{d b}=\frac{k}{h(p) I^{\prime \prime}(A)}<0
$$

If Equation (19) indicates that cooperative profit level $T x$ will decrease according to the increase of RCC manager's decision power for strategic cooperation, Equation (20) indicates that subsidies provided by local government for RCC will increase according to the increase of RCC manager's decision power for strategic cooperation. In other words, the increase of RCC manager's decision power for strategic cooperation can decrease its cooperative profit level so as to gain resource inputs from strategic cooperative partner and demand more subsidies from local government. With the increase of RCC manager's decision power for strategic cooperation, RCC's actions may go against objectives for the promotion of three rural economy and even damage comprehensive interests of three rural economy, as shown in Equation (21).

\section{SOLUTION TO TRILATERAL GAME MODEL}

J. RCC's Nash Equilibrium under the Condition of No Rentseeking

If RCC does not seek for tax preference and policy support from local government, namely, rent-seeking behaviors in economic policies, it is still necessary to distinguish control right of different strategic cooperative profit level. Whether the right belongs to local government or RCC, it is the original value of the whole game process.

Threat points jointly decided by Equation (9), (10) and (11) are recorded as profit level of strategic cooperation, level of policy subsidies and degree of policy easing respectively, presented as $T x_{g}, T_{g}$ and $A_{g}$. Under this condition, Nash equilibrium of local government and RCC is given by the following equation.

$$
\begin{aligned}
& \max _{T, T x}\left[g(T x)-g(p) c(T)+h(p) I(A)-u_{g}\right] \\
& {[b(a p+T-T x-k A)-\bar{u}]}
\end{aligned}
$$

The first order conditions are as follows.

For $T x$,

$g^{\prime}(T x)[b(a p+T-T x-k A)-\bar{u}]-$

$b\left[g(T x)-g(p) c(T)+h(p) I(A)-u_{g}\right]=0$ 
For $T$,

$-g(p) c^{\prime}(T)[b(a p+T-T x-k A)-\bar{u}]+$

$b\left[g(T x)-g(p) c(T)+h(p) I(A)-u_{g}\right]=0$

For $A$,

$h(p) I^{\prime}(A)[b(a p+T-T x-k A)-\bar{u}]-$

$k b\left[g(T x)-g(p) c(T)+h(p) I(A)-u_{g}\right]=0$

By solving, there is

$$
g^{\prime}(T x)=g(p) c^{\prime}(T)
$$

$$
\begin{aligned}
& h(p) I^{\prime}(A)[b(a p+T-T x-k A)-\bar{u}]= \\
& k b\left[g(T x)-g(p) c(T)+h(p) I(A)-u_{g}\right]
\end{aligned}
$$

From the equations above, it can be seen that the optimal profit level of strategic cooperation and transfer payment level of local government are not related to local economic policies, which however are the function of both, meaning that economic policies are influenced by profit level of strategic cooperation and regulation ability of local government.

\section{K. RCC Deciding Profit Level of Strategic Cooperation}

If it is RCC who decides profit level of strategic cooperation, then $T x=T=0$. Under this condition, benefits of local government and RCC are $h(p) I(A)$ and $b(a p-k A)$ respectively; and Nash equilibrium can be solved by the following equation.

$$
\begin{aligned}
& \max _{T, T x, M}[g(T x)-g(p) c(T)+h(p) I(A)] \\
& {[b(a p+T-T x-k A)-b(a p-k A)]}
\end{aligned}
$$

Similar to the above, by solving, there is

$$
\begin{gathered}
g^{\prime}(T x)(T-T x)=g(T x)-g(p) c(T) \\
g^{\prime}(T x)=g(p) c^{\prime}(T)
\end{gathered}
$$

If RCC decides profit level of strategic cooperation, optimal equilibrium is irrelevant to economic policies.

\section{RCC's Nash Equilibrium under the Condition of Rent- seeking}

This part is to prove that since local government's gains from the implementation of preferential tax policy are separable, RCC under the condition of rent-seeking will not change the optimal solution. Similar to the former proving process, the first is to make sure whether cooperative profit level is controlled by local government or RCC under the condition of RCC's rent-seeking, based on which three points can be deducted.

1 ) Director of local governmental controlling cooperative profit level

Threat point of local government and RCC is still given by Equation (7) and (8). Thus, condition of the joint optimal solution is

$$
\begin{aligned}
& \max _{T, T x, M}\left[g(T x)-g(p) c(T)+h(p) I(A)+M-u_{g}\right] \\
& {[b(a p+T-T x-k A)-M-\bar{u}]}
\end{aligned}
$$

The first order conditions are as follows.

For $T x$, there is

$$
\begin{aligned}
& g^{\prime}(T x)[b(a p+T-T x-k A)-M-\bar{u}]- \\
& b\left[g(T x)-g(p) c(T)+h(p) I(A)+M-u_{g}\right]=0 \\
& -g(p) c^{\prime}(T)[b(a p+T-T x-k A)-M-\bar{u}]- \\
& b\left[g(T x)-g(p) c(T)+h(p) I(A)+M-u_{g}\right]=0
\end{aligned}
$$

For $M$, there is

$[b(a p+T-T x-k A)-M-\bar{u}]-$

$\left[g(T x)-g(p) c(T)+h(p) I(A)+M-u_{g}\right]=0$

By solving Equation (31), (32) and (33), there is

$$
\begin{gathered}
g^{\prime}(T x)=g(p) c^{\prime}(T) \\
\left.M=\frac{1}{2}\left\{\begin{array}{l}
{[\beta(\alpha \pi+T-T x)-\bar{u}]-} \\
{\left[g(T x)-g(p) c(T)-u_{g}\right.}
\end{array}\right]\right\}
\end{gathered}
$$

And,

$$
\begin{aligned}
& h(p) I^{\prime}(A)[b(a p+T-T x-k A)-M-\bar{u}]= \\
& k b\left[g(T x)-g(p) c(T)+h(p) I(A)+M-u_{g}\right]
\end{aligned}
$$

Equation (36) means excess profit gained through the even division of cooperative profit between local government and RCC, which is influenced by transfer payment level as well as cooperative profit level and rentseeking level of RCC. However, it is difficult to solve the optimal degree of economic policy level, indicating the difficulty in the establishment of economic policy mechanism in reality.

2) Manager of RCC controlling cooperative profit level

On the condition that RCC decides profit level of strategic cooperation, threat points of both players in the game are determined by Equation (10) and (11). In other words, if cooperative profit of RCC at the threat point is zero, local government will not provide related subsidies 
and therefore profit of both players are 0 and $b a p-k A$. If RCC seeks for tax preferences and policy supports, the optimal solution is the maximization issue as followed.

$$
\begin{aligned}
& \max _{T, T x, M}[g(T x)-g(p) c(T)+h(p) I(A)+M] \\
& {[b(a p+T-T x-k A)-M-(b a p-k A)]}
\end{aligned}
$$

Similar to former analysis, by solving, there is

$$
\begin{gathered}
g^{\prime}(T x)=g(p) c^{\prime}(T) \\
g^{\prime}(T x)(T-T x)=g(T x)-g(p) c(T) \\
M=\frac{1}{2}\{\beta(T-T x)-[g(T x)-g(p) c(T)]\}
\end{gathered}
$$

To sum up, whether under the condition of RCC's rentseeking or not, cooperative profit level of RCC and transfer payment level of local government are the same. In other words, seeking for tax preference and policy support can result in disequilibrium of the development of RCC strategic cooperation mechanism, and even cause profit loss of the whole area. Besides, equilibrium result is independent of economic policy level.

\section{Relation between Transfer Payment of Local Government and cooperative profit of $R C C$}

This part will discuss the influence of enhancing RCC's decision power $\beta$ and strengthen strategic cooperation degree $\alpha$. Since transfer payment of local government as well as economic and cooperative profit of RCC are all independent of economic policy, the influence of economic policy is ignored here to simplify the analysis.

1) Local government deciding strategic cooperation degree

The former part has proved that equilibrium solution is irrelevant to RCC's rent-seeking. Therefore, if cooperation degree and transfer payment are formulated function, by solving partial derivative of $\beta$ in two sides of Equation (39), there is

$$
g^{\prime \prime}(T x) \frac{\partial T x}{\partial \beta}=g(p) c^{\prime \prime}(T) \frac{\partial T}{\partial \beta}
$$

By solving partial derivative of $\beta$ in two sides of Equation (23), there is

$$
\begin{aligned}
& g^{\prime \prime}(T x)[\beta(\alpha \pi+T-T x)-\bar{u}] \frac{\partial T x}{\partial \beta}+ \\
& g^{\prime}(T x)(\alpha \pi+T-T x)=2 \beta g^{\prime}(T x)\left(\frac{\partial T x}{\partial \beta}-\frac{\partial T}{\partial \beta}\right)+U_{g}
\end{aligned}
$$

Where, $U_{g}=g(T x)-g(p) c(T)-u_{g}$
Based on former assumption, $g^{\prime \prime}(T x)<0$ and $c^{\prime \prime}(T)>0$. Therefore, from Equation (36), it can be known that symbol of $\frac{\partial T x}{\partial \beta}$ and $\frac{\partial T}{\partial \beta}$ are different. If $\frac{\partial T x}{\partial \beta}<0$, then $\frac{\partial T}{\partial \beta}>0$ and $g^{\prime}(T x)>0, U_{g}>0$. Therefore, the left side of Equation (37) is greater than zero while the right side is uncertain and $\frac{\partial T x}{\partial \beta}>0$ is also uncertain. If $U_{g} \approx 0$, the right side is less than zero when $\frac{\partial T x}{\partial \beta}<0$, which is obviously contradicting. Therefore, $\partial \beta, \frac{\partial T}{\partial \beta}<0$ The above deduction shows that if local government possesses absolute power to decide RCC's strategic cooperation degree, RCC's cooperative profit level can be promoted by perfecting strategic cooperation mechanism and at the same time related subsidies for strategic cooperation reform will decrease.

If cooperation degree and related subsidies are function of $\alpha$, by solving partial derivative of $\alpha$ in two sides of Equation (30), there is $\frac{\partial T x}{\partial \beta}>0$ and $\frac{\partial T}{\partial \beta}<0$. This indicates that strategic cooperation of RCC can not only increase its cooperative profit level but also reduce local government's subsidies to RCC.

2) RCC deciding strategic cooperation degree

If RCC takes control of cooperation degree, the game result will be different. Let's first discuss the influence of strategic cooperation. By solving partial derivative of $\beta$ in two sides of Equation (39) and (40), combined result of Equation (35), there is

$$
\begin{gathered}
g^{\prime \prime}(T x) \frac{\partial T x}{\partial \beta}=g(p) c^{\prime \prime}(T) \frac{\partial T}{\partial \beta} \\
-g^{\prime \prime}(T x)(T-T x)=2 g^{\prime}(T x)\left(\frac{\partial T x}{\partial \beta}-\frac{\partial T}{\partial \beta}\right)
\end{gathered}
$$
$\frac{\partial T}{\partial \beta}$

According to Equation (45), symbol of $\frac{\partial T x}{\partial \beta}$ and are different. Combing $g^{\prime \prime}(T x)<0, g^{\prime}(T x)>0$ and, there is $\frac{\partial T x}{\partial \beta}-\frac{\partial T}{\partial \beta}>0$ and thereby $\frac{\partial T x}{\partial \beta}>0 \quad \frac{\partial T}{\partial \beta}<0$. Therefore, if it is RCC who decides cooperation degree, the result of strategic cooperation is also the promotion of cooperative profit level and decrease of local government's subsidies. 


\section{CONCLUSION AND SUGGESTION}

Based on the game model of local government and RCC constructed in the thesis, it can be confirmed that the essence of game is how to define strategic cooperation degree and profit level of RCC in the process of strategic cooperation. The nature of RCC decides that it pays more attention to profits of stockholders and cooperators while local government is inclined to enable RCC to take an active part to strategic cooperation reform. In the selection of strategic cooperative partner, what local government focuses on is whether the promotion of RCC's strategic cooperation level can strengthen local government's economic policy as expected. In the trilateral game model, with different stakeholders taking control, there are conclusions as follows.

\section{A. Local Government Being Strong Support for the Success of RCC Reform}

If local government possesses control power of strategic cooperation reform, it will reduce relevant subsidies for RCC in the process of strategic cooperation, and the comprehensive cooperative profit level will be increased. As local financial agency, RCC's market mechanism reform cannot leave guidance of local government. Due to the special historical conditions of China, local government is always RCC's investor and risk bearer. Without policy guarantee of local government, capital for strategic cooperation can hardly flow to three rural economy. Without regulation and control of local government, RCC may go against the goal to finance three rural issues but purely pursue maximization of its benefits, which will damage interests of local government and even central government. Therefore, before finding a practical way to RCC reform, local government should not give up its control and management power for RCC's strategic cooperation.

\section{B. RCC Lowering Dependence on Local Government through Reform}

If RCC possesses control power of strategic cooperation reform and its decision power for strategic cooperation gets promoted, relevant subsidies provided for RCC by local government will also be reduced, and the comprehensive cooperative profit level will also be increased. Now the supervision mechanism of RCC in China has been gradually included in the general framework featuring nation's macro-control and strengthened supervision, provincial government's administration according to law and implementation of policy, as well as RCC's self-discipline and taking its own risk. In order to establish sound internal control mechanism, RCC has to achieve self-operation and self discipline at its own risk. RCC's introduction of strategic cooperative partner should not only satisfy its internal demand impetus but also conform to Guidance on Accelerating Equity transformation of Rural Cooperative Financial Agencies. Since strategic cooperation reform is a fundamental, complicated and long term system engineering of RCC, RCC must have a right knowledge and understanding of the reform purpose and have strategic thoughts on whether to introduce, what kind of cooperative partner is qualified to introduce and in which way to introduce a strategic cooperative partner.

\section{Success of Reform Contributing to Both Local Government} and $R C C$

Whether control power of strategic cooperation reform belongs to local government or RCC, the promotion of RCC's strategic cooperation degree can increase profit level, enhance development of three rural economy, and reduce local government's subsidies for RCC. No matter which party is in the dominant position, strategic cooperation should be established on the basis of equality and mutual benefit, which is the foundation for both party to maintain deep and sustaining cooperation. This is of great importance for RCC's strategic cooperation reform. Compared to its strategic cooperative partner, RCC, mostly with small and medium-sized organization structure, is disadvantageous in personnel quality, operation philosophy, product innovation and risk management, which does not mean that RCC should be subject to its partner in the future cooperation. Local government is not only the direct supervisor of RCC but also provides RCC with resource support and risk guarantee, which can also be considered as one kind of strategic cooperative relation. In the sense of sociology, local government and RCC as well as RCC and its strategic cooperative partner are strong ties while local government and strategic cooperative partner belong to weak tie. However, it is the numerous weak ties that create the atmosphere of financial system innovation in the whole region and even nationwide.

All in all, the key to RCC's strategic cooperation reform is to establish work coordination mechanism that can take three stakeholders into consideration, which is also the guarantee for the durable and mutually beneficial cooperation among the three stakeholders. In the promotion of specific projects, local government should assist RCC to establish scientific research mechanism and help strategic cooperative partner to grasp as much information on three rural issues as possible through multiply channels, who should also respect each other, take others' advice, and create harmonious cooperation atmosphere.

\section{REFERENCES}

[1] TANG Xiao-jiong, On the Structure of Corporate Governance of Rural Credit Cooperatives $[\mathrm{J}]$. Journal of Northwest A\&F University(Social Science Edition), 2009,9:11-13..

[2] ZHOU Dongyan. On How to Improve the Innovative Services of Rural Credit Cooperatives [J]. Economic Research Guide,2013,36:125-126.

[3] Duyster GM, Kok G, Vaandrager M. Crafting Successful Strategic Technology Partnership [J].R\&D Management,1999,29:343-351.

[4] C.Jay Lambe, Robert E.Spekman. Alliances , External Technology Acquisition, and Discontinuous Technological Change[J].Journal of Product Innovation Management, 1997, 14(2) : 201-116.

[5] Robert J.Vokurka, Scott W.O' Leary-Kelly. A Review of Empirical Research on Manufacturing Flexibility [J] . Journal of Operations Management, 2000, 18(4): 485-501.

[6] Joel Bleeke, David Emst. The Way to Win in Cross-Border Alliances[J]. Harvard Business Review, 1991, (11-12):127.

[7] Benton, W.C., \& Maloni, M. The influence of power driven buyer/seller relationships on supply chain satisfaction [J]. Journal of Operations Management, 2005, 23(1): 1-22.

[8] NI Huihua. Transaction cost economics: Past, Present and Future[J]. Management World , 2004, (12): 146-153. 
[9] HUANG Kainan. Evolutionary Games and Evolutionary Economics [J]. Economic Research Journal. 2009, (2): 132-145

[10] LI Qi. Game Analysis and Path Selection during the China Rural Credit Cooperative Institutional Evolution [J]. Rural Economy, 2009, (04): 64-66..

[11] WEI Jinming, CHEN Min. Game Analysis of How Grass-roots Government Intermeddling Rural Credit Cooperatives Under New Management System[J]. Journal of Financial Development Research, 2009, (2): 71-74.

[12] KONG Rong, LI Xing-ping. A Study on the Credit Game Relationship between Poor Farmer and Rural Credit Cooperatives
Based on Trust: Shaanxi Province as an Example [J]. Journal of Chongqing University (Social Science Edition), 2010, 16(5): 1-7.

[13] HANG Le-zhu, LIU Qi .The Analysis of Credit Village Construction on a Cooperative Game between Local Government and Rural Credit Cooperatives [J]. Journal of South China Agricultural University(Social Science Edition), 2011, (03): 1-6.

[14] Zhang Yaofeng, Min Qiuhong. Evolutionary Game Analysis on Credit Relation of Rural Credit Unions and Farmers under Asymmetric Information [J]. Value Engineering, 2012, (03): 122123. 